\title{
Editorial
}

\section{OPERATIONS RESEARCH: THEORY AND APPLICATIONS}

One of the main goals of Lithuanian Operations Research Society is to support young researchers working in the area of operations research. The Society together with Institute of Mathematics and Informatics, and Vilnius Gediminas Technical University organized the Conference Operations Research: Theory and Applications in Vilnius on May 26, 2006. The Conference was also supported by Kaunas University of Technology, M.Römer University, Šiauliai University, and Lithuanian Union of Young Scientists. The aim of the Conference was to give an opportunity to young researchers to present and discuss their work results. Besides young researchers several recognized Lithuanian experts in the field also participated at the Conference, discussed the presentations and gave their advise to the speakers with respect to their further work. The presentations were grouped according to their themes into the following sessions:

- optimization methods and their applications;

- metaheuristics and data mining;

- game theory and mathematical economics;

- modeling of various networks;

- applications of operations research in environmental protection and sustainable development;

- decision-making and decision analysis.

The Conference program included 19 presentations. The participants represented several Lithuanian institutions: Institute of Mathematics and Informatics, Vilnius Gediminas Technical University, Vilnius Pedagogical University, Kaunas University of Technology, and some others. The research papers included into this issue have been refereed by experts in the field. On behalf of the authors and the Conference organizers I thank the reviewers for their important contribution.

The presentations show the main trends in the research of young Lithuanian researchers working in the area of operations research. Successful research was demonstrated in visualization of multidimensional data by young researchers of the Institute of Mathematics and Informatics. Important problems of simulation and modeling have been solved by the representatives of Vilnius Gediminas Technical University and Kaunas University of Technology. Interesting applications of operations research methods in civil engineering was presented by several authors from Vilnius Gediminas Technical University. Several discussions on optimization methods were initiated by the authors associated with the Institute of Mathematics and Informatics.

Although information about the Conference had been widely disseminated in due time, not all the groups of researchers working in the field of operations research were represented. Possibly some researchers do not consider the conferences of young researchers as sufficiently serious, however, this Conference demonstrates just the contrary. The success of the Conference raises hopes that similar conferences will become annual attended by the majority of young researchers engaged in operations research.

Antanas Žilinskas 